This document has been downloaded from

TamPub - The Institutional Repository of University of Tampere

Post-print

The permanent address of the publication is http://urn.fi/URN:NBN:fi:uta-201412122426

Author(s):

Närvänen, Elina; Kartastenpää, Elina; Kuusela, Hannu

Title: Online lifestyle consumption community dynamics: A practice-based analysis

Year: 2013

Journal Title:

Journal of Consumer Behaviour

Vol and number:

$12: 5$

Pages:

358-369

ISSN:

1479-1838

Discipline:

Business and management; Sociology

School /Other Unit:

School of Management

Item Type:

Journal Article

Language:

en

URN:

URN:NBN:fi:uta-201412122426

URL:

10.1002/cb.1433

Subject:

kuluttaminen; elämäntyyli; ruoan kuluttaminen; identiteetti; verkkoyhteisö; netnografia; consumption; lifestyle; food consumption; identity; online community; netnography

All material supplied via TamPub is protected by copyright and other intellectual property rights, and duplication or sale of all part of any of the repository collections is not permitted, except that material may be duplicated by you for your research use or educational purposes in electronic or print form. You must obtain permission for any other use. Electronic or print copies may not be offered, whether for sale or otherwise to anyone who is not an authorized user. 


\title{
Online lifestyle consumption community dynamics: A practice-based analysis
}

\begin{abstract}
The purpose of this study is to identify and categorize the discursive practices through which consumers negotiate a lifestyle-related identity in online lifestyle consumption communities. The empirical case is a very active community of consumers who adhere to the Low Carb - High Fat (LCHF) diet. The paper contributes to communal consumption literature by showing how a lifestyle identity and the community evolve together. Focusing on an online community with lifestyle focus differentiates this study from previous research because nutritional choices influence the consumers' everyday life in a comprehensive manner. By employing a netnographic analysis on discussion board messages, eleven discursive practices are identified. These practices are categorized according to confirming/challenging and self-directed/community-directed dimensions. The paper provides a typology of online community dynamics, emphasizing the importance of challenging practices for community development. It also has important implications for companies who wish to understand food lifestyles and develop online platforms for their customers.
\end{abstract}

Keywords: online communities, identity, discursive practice, lifestyle, netnography 


\section{Online lifestyle consumption community dynamics: A practice-based analysis.}

\section{INTRODUCTION}

Online consumption communities are "affiliative groups whose online interactions are based upon shared enthusiasm for, and knowledge of, a specific consumption activity or related group of activities (Kozinets 1999, 254)". They are platforms of collaboration that engage their members and provide new opportunities for marketers as well (Kozinets et al., 2008). The power of communities in the marketplace cannot be underestimated, because the social links between consumers provide them value and important resources that empower them to construct their identity as well as influence each other's consumption choices. Online communities also give consumers a forum for effective and anonymous sharing of experiences, feedback and peer support.

A community of consumption may focus on a single brand or a subculture, consumption activity, or lifestyle. In the search for ingredients of identity, online communities of consumption are becoming increasingly important, because they provide rich cultural meaning and affirmation of group belongingness. For companies, learning to understand and interact with communities is essential. More research is needed on how communities evolve. In online communities, the role of members themselves as community developers is crucial. Building identity and contributing to community development entail complementary practices that need to be studied to understand the dynamics of online communities better. This paper contributes by discussing these dynamics through a practice theoretical framework.

In the literature, consensus and agreement that lead to social support and reinforced bonds between the community members have been emphasized. Yet, online community members differ in terms of their membership length and experience and in terms of their orientation to the community (deValck, 2007; Kozinets, 1999). It is likely that this heterogeneity causes potential conflict or at least disagreement over priorities, norms and rules of behavior. It is well known that consumers' identities are fragmented and often characterized by contradiction (Cova and Elliott, 2008; Firat and Dholakia, 2006). Thus, when the community revolves around a fundamental identity pursuit, such as a comprehensive lifestyle instead of just a single brand, active negotiations instead of unison and conformity are even more likely. This paper contributes to understanding the tensions and active negotiations in an online lifestyle consumption community.

We study a very active online lifestyle consumption community for low-carb/high-fat (LCHF) dieters. The majority of online community research discusses brands of consumer products (Algesheimer et al., 2005; McAlexander et al., 2002; Muñiz and O'Guinn, 2001; Muñiz and Schau, 
2005), or large-scale media franchises and leisure activities (Kozinets, 2001; Schau et al., 2009). More research is needed on communities with lifestyle focus, because lifestyle choices have a more comprehensive influence over the consumers' everyday life, permeating many kinds of social situations. The role of online support groups as important forums for social support has been noted by other fields, such as health care and medical science, yet they have not been extensively studied from the point of view of consumer research (Ballantine and Stephenson, 2011). Food has a strong influence on identity and different lifestyle phenomena such as sustainable consumption, or different food regimes and philosophies are increasing their popularity. Therefore, it is essential to study the contexts, practices and communities that are related to the pursuit of these identities. Our study complements existing theory by drawing from this rich and unexplored territory.

The objective of this study is to identify and categorize the discursive practices through which consumers negotiate a lifestyle-related identity in online lifestyle consumption communities. By analyzing shared practices instead of individual consumers, our study follows recent calls for collective action of consumers through practice theory (Schau et al., 2009; Warde, 2005).

\section{THEORETICAL BACKGROUND}

\section{Online communities}

The online technology has advanced rapidly and brought a variety of different formats and platforms. Social media, such as online communities, blogs and microblogs offer consumers new options for participating in social interaction online (Kozinets et al., 2010). This has meant a change in consumer culture as well (Kozinets, 2002). Online communities offer consumers different narratives and cultural models and help to identify consumption-related identities (Goulding et al., 2002; Rokka and Moisander, 2009). According to Schau and Gilly (2003, 387), expressing one's identity might be even easier online since consumers do not necessarily need to own concrete consumption objects, but instead they can take advantage of virtual products, signs and symbols.

In a consumption community, online or offline, a consumer learns identity-related practices and how to define their identity in relation to others. Consumption knowledge and identity is developed in concert with social relationships (Bagozzi and Dholakia, 2006; Kozinets, 1999). The communities help consumers regain a sense of social belonging while being able to express their individuality too (Cova, 1997; Cova and Cova, 2002; Goulding et al., 2002). The in-group offers a feeling of belonging whereas distinguishing from the out-group gives a feeling of uniqueness (Jenkins, 1996). Compared to offline communities based on face-to-face communication, online communities offer more possibilities for many-to-many interaction because communication is 
asynchronous and people may read and respond to others' messages in their own time (Etzioni and Etzioni, 1999). On the other hand, the ability of online communities to retain and archive messages helps the community to form a sense of history and continuity, which is important in terms of community formation (ibid.). Yet, so far the dynamics of how online communities evolve have not been studied extensively. Our empirical case provides data from a longer time period, which is why it enables us to look at the dynamics more fully.

The online community also enables consumers to interact without being in close proximity to one another, allowing people to socialize even if they are home-bound. Even if the consumer pursuing a lifestyle identity does not share their goal with their family or friends, they can easily find similar others online. Online communities may help consumers to deal with stigmatized parts of the identity since it is easier to find similar others and they may talk anonymously (Kozinets, 2001; McKenna and Bargh, 1998). This is a benefit especially regarding personal concerns and problems, such as health issues (Ballantine and Stephenson, 2011; Liang and Scammon, 2011).

Online communities thus appear to be more effective in helping consumers build a consumption-related identity than offline ones. Especially in health-related issues, consumers prefer the anonymity, objective feedback and reduced role obligations that they can have online as opposed to discussing with their close family or friends (Wright et al., 2010). Compared to face-toface communities, online communities allow members to play with identities through anonymity. The problem of faking identity and disturbing the discussion purposefully must be taken into account in computer-mediated communication. Mechanisms to build trust and reputation are often needed and emerge frequently in online communities (Rheingold, 2002). In the specific context of a food lifestyle that entails the adoption of a complex system of consumption-related knowledge, faking is easily noticed by the more experienced members. Members also engage in policing and monitoring each other in the community, as will be seen in our empirical analysis. Thus, we find that by analyzing this particular lifestyle community, we are able to really grasp the way community and self are developed together through discursive practices.

Online community members are believed to have common values, norms, rituals and rules (Fernbank, 1999; Muñiz and O'Guinn, 2001). This shared cultural order affects many areas of their behavior, including consumption (Kozinets, 2002; Schau et al., 2009). Bagozzi and Dholakia (2006) argue that the stronger the social identity, the more a consumer is likely to participate in the online community. These characteristics that emphasize uniformity and commonalities between members have been found especially in communities of commercial brands or companies (Algesheimer et al., 2005; Cova and Pace, 2006; Kozinets, 2002; Muñiz and Schau, 2005). On the other hand, the consumption tribe concept considers more fluid and momentary, less structured collectives united 
by shared emotional experiences and rituals (Cova and Cova, 2002). The emphasis has been on the "linking value" of products and services for tribes instead of looking at identity negotiation processes facilitated by the social interaction in communal contexts. Lesser research has also been devoted to lifestyle communities that are not based on a single focal brand where also member heterogeneity and possibility of conflict exist (deValck, 2007; Heinonen, 2011). DeValck (2007, 262) suggests that the focus of online communities continually shifts from precedence to individual needs to group needs. She also argues that practices in online communities are characterized by three tensions: those between core members for status, those between core members and the larger community about appropriate norms and practices and those between different sub-groups within the larger community. Our study builds on this and teases out more clearly the differences between self-oriented and community oriented as well as maintaining versus challenging practices. In other words, the focus in our paper is on practices themselves. In contrast to just discussing the consumption activity of eating/cooking online, our empirical case entails a complex knowledge system around a lifestyle that the members are trying to adopt.

\section{Food and lifestyle identities}

Food is an integral part of consumer culture and consumption lifestyles. Nutrition is important for consumers because it has a direct impact on their health and identity (Kniazeva and Venkatesh, 2007). Through food choices, a consumer can define who they are or want to be (Belasco, 2008; Fischler, 1988; Rozin, 1999). Consumers' identities are plural and they are constantly modified in relation to the surrounding cultural system (Hall, 1992). Thus, cultural discourses related to being in control of your body and following the norms of good nutrition affect consumers' pursuits for desirable selves and sustain whole industries around products and services related to health and dieting (Thompson and Hirschman, 1995; Thompson and Troester, 2002). Yet the contradictory meanings related to food consumption make the choices difficult for consumers (LeipämaaLeskinen, 2007). There are also alternative norms such as the trend toward organic and unprocessed food (Honkanen et al., 2006; Hughner et al., 2007).

In this research, identity is understood as a "reflexively organized endeavour" (Giddens, 1991: 5). People face a diversity of options and choices that they must make in order to sustain a sense of self. Nevertheless, individuals cannot make choices independently. All identities are social, since they are always socially constructed and under social negotiation (Cherrier, 2007; Jenkins, 1996). Identities always exist within power relations; they are struggled over and negotiated (Foucault, 1980). When a wealth of information is available through the media, friends, the internet, and 
doctors, it is difficult to evaluate which source is trustworthy. Thus, the more information we have about food, the greater uncertainty there is about what is safe or good to eat (Brunel and Pichon, 2004; Järvelä et al., 2006). Consumers' trust in institutions such as national health officials or doctors is also decreasing due to heightened cultural awareness of the risks associated with technological and scientific development (e.g. The Edelman 2012 Trust Barometer). Hence, different peer groups and collectives that criticize and offer alternatives to the expert systems play a significant role in how consumers construct their sense of self (Thompson, 2005).

It has been argued that online community memberships evolve from casual acquaintances toward more intimacy, routine and commitment, but these changes may not be static and linear (Alon et al., 2005; Heinonen, 2011). Similarly, a social identity as a LCHF dieter, for instance, is developed gradually as the members gain more knowledge about the lifestyle. The methodological implication is that to study lifestyle-related identities, we need to look at how they negotiated in social interaction through discursive practices (Catterall and McLaran, 2001; Shankar et al., 2001).

\section{METHODOLOGY}

The data has been generated from the online lifestyle consumption community of Karppaus.info, a Finnish online community for LCHF dieters. The LCHF diet is based on restricting the intake of carbohydrates. On the other hand, sufficient use of fat is emphasized as important for health and weight loss. The diet represents a holistic and nuanced alternative lifestyle choice for consumers, and influences their purchase behavior to a large extent. For instance, in Finland, the trend for LCHF has caught on rapidly during the recent years. It was reported in the media before Christmas of 2011 that the demand for butter and eggs dramatically increased to such extent that retailers had problems to refill their shelves. Food manufacturers, on the other hand, have introduced LCHF-friendly convenience foods and meals to the market. There has also been a heated discussion in the media for and against the diet, played out between the "LCHF gurus" and representatives of official nutrition authorities.

The discussion board Karppaus.info has functioned since 2004 and there are approximately 30000 registered members. There are almost 50000 message chains on the discussion board and hundreds of messages are posted every day in several different message chains. This level of activity makes the community a good choice for netnographic analysis. Netnography investigates the social and cultural aspects of online communities (Kozinets, 2002). It enables the study of new forms of community and consumption-related learning (Sandlin, 2007). Researchers disagree on the extent to which the identity and presence of the researcher should be disclosed to the community 
members (Langer and Beckman, 2005). In this study, the researchers did not introduce themselves on the discussion board or take part in the discussion. The aim was to identify discursive practices from the textual materials, and the nature of the discussion was public. We also did not want to make unwelcome requests to the community (Catterall and Maclaran, 2002). However, we familiarized ourselves with the culture of the community through following the discussion board unobtrusively for ten months.

Insert Table 1 about here-

The data were generated using theoretical sampling. Due to the high level of activity on the discussion board, it was not possible to analyze the entirety of the discussions. In order to get a complete overview, we followed the discussion board intensively and familiarized ourselves with the phenomenon also by following the media, blogs and other discussion boards online. A longterm engagement with the phenomenon helped us gain a rich perspective through identifying the typical features and characteristics of the community, as well as distinguishing the ordinary from the unusual.

This pre-understanding guided the data generation process. For further analysis, we selected message chains that best maximized the opportunities to develop concepts, uncover variations and identify the relationships between them (Corbin and Strauss, 2008). This was an iterative process of selecting diverse message chains from the various sections of the discussion board while simultaneously developing our understandings and interpretations.

The analysis was directed at identifying collective and shared patterns of interaction i.e. discursive practices. In other words, it was not the aim to study the actions or thoughts of individual consumers separately (Halkier and Jensen, 2011). This type of orientation enables the researchers to avoid problems of consumers possibly faking their identity. It is also not possible to link the behavior of single consumers with their life contexts (Arnould and Wallendorf, 1994). However, as Kozinets (2010: 133) argues, the target of analysis in netnography is not a single consumer but cultural talk. This means that each discussion board message is considered as a social act, making it irrelevant to know who is doing/saying, but instead, to understand the field where communication and culture takes place.

In practice, we used sensitizing concepts (Corbin and Strauss, 2008) from previous research to pursue the meanings, themes and categories in the textual data. After the first round of analysis, four categories emerged through comparing and abstracting the practices to a higher level of 
analysis (Spiggle, 1994). The process was iterative: the messages were read through multiple times and more data was generated as the interpretations started to emerge. Finally, the principle of saturation was used to identify the point where no further data was needed. ${ }^{1}$

\section{FINDINGS}

-Insert Figure 1 about here-

Based on the data analysis, eleven discursive practices through which consumers build their identity and develop the community were identified. These practices were arranged according to two dimensions. These dimensions emerged inductively from the data analysis and are not directly based on previous literature. Self-directed discursive practices are more important for the individual whereas the community-directed ones are significant to the community's development. This dimension bears some resemblance to Kozinets' (1999) notion of developing consumption knowledge and social relationships simultaneously. Confirming practices reinforce the community's norms and reproduce established cultural meanings, whereas challenging practices are related to negotiating meanings and have more potential to change the individual and community understandings. This dimension was identified as a result of engaging with the literature on food consumption and its contradictory nature. Food consumption is full of contradictions and tensions, and this is reflected in the practices of the online community as well, differentiating it significantly from the practices found in other online communities.

\section{Self-directed and confirming practices}

The practices in this category indicate that the members are absorbing information and support from the community. The first identified practice is that of seeking information and feedback. At first, the LCHF lifestyle may seem difficult and complex, and it is therefore essential to get advice and feedback from more experienced members:

Somebody wrote that you cannot have too much protein, another tells you to count the calories, and still another says you should have more fat everywhere...I'm drowning

\footnotetext{
${ }^{1}$ To illustrate the practices in the paper, we have selected quotations from the data that depict them particularly well. In the quotations, emoticons have been translated from pictures to words and are contained within asterisk marks (e.g. *smiling*).
} 
in this information flood and cannot decide what to do. [...] All tips, advice and encouragement will be happily received. [9.9.2010; beginning the lifestyle]

This post clearly indicates that learning to follow the LCHF diet is a challenge that requires resources, time and effort. The social support of other members is an important resource. The practice also entails becoming familiar with the jargon that is used on the discussion board: concepts referring to particular nutritional substances, particular styles of LCHF dieting and even certain food brands that have their own nicknames:

I thought I bought "bearded man" [a nickname for a yoghurt brand that has a photo of a bearded man depicted in the package] but it says Bulgarian yoghurt on the package.... What did I buy? Is it right or wrong? *confused * [10.6.2006;"bearded man"]

The second identified practice is that of evaluating and relating. It involves members comparing the LCHF -lifestyle to their other relevant identities, such as parent, environmentalist or nurse. The knowledge gained about the diet is evaluated in terms of how it fits other areas of the person's life. It is a necessary step towards engaging more fully in the lifestyle. As found in a study of sustainable lifestyle, consumers are more likely to integrate particular consumption practices into their existing identities than adopt a totally new one (Black and Cherrier, 2010). In our data, the importance of maintaining social relationships was emphasized in opposition to strictly following the diet:

I don't have a problem when visiting friends; I can drink coffee without having pastries fairly discreetly, and eat the meat stew with salad. The only problem is with my mom; she is a fantastic cook and wants to make delicious food for everyone; so in order to save her the trouble, I even eat mashed potatoes without complaining. A little too much carbohydrate for me is a lesser evil than the trouble for her. [30.11.2010; being a LCHF dieter in secret]

Living the LCHF lifestyle is a constant negotiation of priorities and finding your own way to cope socially while interacting with people who do not share the lifestyle. Some do not follow the norms of the diet when on holiday for example, whereas others are ready to sacrifice other things in their lives.

For me, it would be easier to take my own food with me, if the place I'm visiting is not familiar with LCHF. It just makes it so difficult when you have to go through everything you cannot eat. But on the other hand, bringing your own food is such an 
insult?? After this, you probably understand why I don't like going visiting, because it is always so difficult. [12.2.2010; what is the most challenging aspect of the LCHF lifestyle]

Our data has similarities with Kozinets' (2001) data on the stigmatized identities of Star Trek fans and how acknowledging their identity in public may function as a path to a stronger collective identity. Beginners in LCHF may still want to hide their lifestyle by using inventive means, even feeling ashamed of their consumption:

As I am only beginning, I will be a secret LCHF dieter. I want to see whether this is for me in the long run. [30.9.2010; being a LCHF dieter in secret]

[...] I was going to make myself a cup of cocoa with cream but I was ashamed to pour the cream in the mug when my roommate was in the kitchen, so I waited 'til she was gone before I made my drink. My roommate had just been making herself some light, sugary porridge for supper...And yet I was the one feeling ashamed? [31.10.2008; whether the members are ashamed about the great amount of fat when they are in the company of people they know]

However, LCHF dieters are faced with the more mundane field of eating, where they have to constantly make legitimate decisions. The decision to be proud of the lifestyle is supported by the celebratory and encouraging posts by other members:

Why on earth should you have to hide what you're eating? It's your own thing. It doesn't concern anyone else. If you've just started, you may feel that you need to explain yourself all the time. But don't bother so much. You have the power over your own life! [1.10.2010; being a LCHF dieter in secret]

An LCHF dieter needs to constantly reproduce a sense of being in control of her self (Giddens, 1991). The data shows the body as an important medium in constructing the LCHF identity. Controlling the body and listening to what it wants are complementary goals:

I have little by little learned to listen to my own body...I can now stop eating in good time. Sometimes I wonder how I can be satisfied with such a small amount of food when I used to empty pans and pots without thinking much...except afterwards...[14.5.2010; the good things that the lifestyle has brought in consumers' lives] 
The third identified practice is that of seeking social confirmation and emotional support. The members try to convince themselves and others that they are capable of committing to the LCHF lifestyle and practicing it according to the community's norms. By reporting their progress, for instance how much they have lost weight, the members seek esteem as LCHF dieters. Knowledge of appropriate foods is posted, paying particular attention to explain or apologize for all the items that are inappropriate:

In my fridge, I have different kinds of vegetables and roots...cream, fatfree milk for my husband, "bearded man", a couple of different sorts of cheese, canned tomatoes, bacon, meat spreads and sausage (for my husband, I rarely eat those), apple jam, many sorts of jams from my previous life (I should throw them away), peppers, canned beetroot and cucumber, olives, salad dressings also from my previous life. My cupboards only contain spices; I gave all the rice, pasta, noodles and macaroni to my daughter-in-law! I used to have all types of those... [22.9.2010; members list the contents of their fridge/cupboards]

Members also hype their purchases of well-known LCHF products and brands. While avoiding fat is the norm in official health recommendations, the LCHF diet celebrates it. Talking about fat helps the members to differentiate themselves from outsiders, and therefore reinforce their identity:

I'm telling you, FAT is really an LCHF dieter's best friend! At the beginning of the project, at the end and in every possible stage in-between! [18.1.2007 in a public diary at the discussion board]

Peer experiences and empathy are sought for the problems and challenges encountered while adopting the LCHF lifestyle:

For instance, take tonight. I had eaten all my designated meals and like a light bolt from the sky, HUNGER caught me off guard (I suspect it is more just a feeling) and off I go to the fridge...I ate some sausage and butter with eggs. Now I'm feeling regret. [sad smiley] Bad conscience. Are there any partners in crime? [22.9.2010; what the members regret eating]

[A response to the above] You were hungry. Why worry if you were satisfying your hunger. Your body knows what it wants.

[Another response] Don't worry. The things you ate were very LCHF-appropriate. 
There is no reason to feel guilty!

[Another response] It's not the point to eat three meals necessarily every day. Not everyone does that. You should eat at your own pace and listen to your own sentiments, nobody is counting!

\section{Self-directed and challenging practices}

The practices in this category are characterized by transformation of the self with the help of the community. First, through revising beliefs, members question their beliefs and understandings about the diet; both those that they have learned from the community as well as from the media and elsewhere. The stereotypical understandings of LCHF are gradually changed as the members familiarize themselves with the discussion board:

I started to read this website first very skeptically ("animal fat cannot be healthy and surely it is not worth it for me because I'm not trying to lose weight and I don't eat meat"), until little by little I was persuaded to try and even register myself in the forum. * smiling* [22.9.2010; where new LCHF dieters got their inspiration for starting the lifestyle]

The support of the community is needed to confirm the new insights and reinforce the decision to engage more fully, for instance whether the lifestyle is too demanding.

Can you tell me whether this low carb diet will be expensive, I mean in the way that I could not afford to lounge in cafes during the summer or buy new shoes (I'm so poor, you see)...If this is the case, then I will continue eating beans and rice and just try to eat less and exercise more. [8.3.2009; how expensive the LCHF lifestyle will become] [a response to the above] ...I forgot to say that I'm poor like you, but LCHF has made my food bill smaller when I don't have to buy any unnecessary things.

Many members first feel that the LCHF is just going to be a temporary diet for them, but end up revising this understanding as well, as they gain more experience:

I haven't been following the LCHF fully before but I've read a lot about it...Now after five days I'm planning to make this a lifestyle, since the foods taste 100 times better than "regular foods" *clapping hands* Big thanks to the artists at the recipe section! [21.9.2010; how to prepare a dinner menu] 
The second practice is that of developing a personal style. With the community's help, individuals learn how to personalize and customize the LCHF norms and guidelines to fit their own lifestyle better. Thereby, the members are allowed uniqueness instead of blindly accepting a shared set of norms and practices. One of the community's norms is that each member should adapt the LCHF diet in their own way and always question everything.

LCHF is not the newest Wonderdiet. It is a lifestyle and about listening to your own body. There are different styles and you can choose the style that fits you personally.

What suits one, does not necessarily suit another. [25.2.2009; what LCHF is all about]

Thus, especially concerning communities related to lifestyles, consumers accept and expect for there to be differing opinions and viewpoints. As evidenced also in Thompson and Troester's (2002) data on natural health consumers, being able to integrate pieces of knowledge together is part of the ideal self-construction:

You can play with diets, you don't have to commit to them like an ideology or a religion. Italian food is one style, Chinese food another, LCHF a third, vegan diet a fourth, living food the fifth and so on. If your body is ok with it, you can change your style at every meal. For me and my body, LCHF is the general style under which I can eat whatever I please whenever I want. [11.9.2009; what members think about people eating raw food or superfood]

Our data shows how the community helps consumers to access the collective wisdom and adapt it to devise their own personal styles. The consumers prioritize values differently; for instance, some emphasize authenticity, whereas others think that improvising and inventing dishes is ok:

To me, the best LCHF food has genuine ingredients and tastes and is prepared in a simple and clear manner; not meringue pie or low-carb pizza that does not even taste like real pizza. [27.8.2009; replacing regular meals with "fake" LCHF meals]

[a response] For me, the dish I make in the glass casserole dish with sausage-cheeseketchup-minced meat-pineapple-cheese composition is pizza. Aren't Samsung and Ericson mobile phones too, even though the original was made by Nokia.

\section{Community-directed and confirming practices}

The three practices in this category concentrate on reinforcing the community together. The first practice is building a relationship with the community. Users are engaged in reflecting and 
comparing themselves with others.

Currently I'm looking for my own style and the foods that suit me, and other things, so becoming a LCHF person is a continuing, living process. Here you can find an astonishing number of clever posters to talk with, so it's easy to continue. [21.2.2011; changes in thinking while adopting the LCHF lifestyle]

Members find it important not only to get information from the discussion board, but to also give something back, in the form of reporting their progress, and sharing recipes, for instance.

During the last week, I have managed to cook such delicious food (considering my special tastes) that I have almost burst into tears. Of course, I will continue cooking and every time I'm about to cry when eating, it deserves to be reported here. [27.8.2010; public dieting diary]

More experienced members also take on roles they consider important in terms of the community as a whole. Reciprocity is an important element of community building and is even more important in online communities where members need to build trust and reputation to overcome the fact that they cannot ascertain each other's purposes or identities face-to-face. In online communities, generalized reciprocity often emerges, because helping others provides members with esteem. Because the community is not managed by any external authority, members' voluntary behavior is also essential for community survival. Thus, members help others and do not expect the favor to be returned directly but somewhere along the way. Reciprocity also enhances commitment to the community (Chan and Li, 2010).

I have now started to link necessary discussion chains directly to those people who need help, I hope nobody minds. It is handy to read a long chain of messages about the same topic, isn't it? ... This board will never die when "elders" post regularly and newcomers follow behind them. [27.10.2005; whether newcomers are allowed in the community]

Members also contribute to the discussion board through their food or weight loss journals. By building their symbolic capital on the LCHF diet through learning its nuances and experimenting with different foods, the members are able to take on different roles and raise their social status within the community (Schau et al., 2009). The divisions between experts and newcomers are clearly visible; becoming an expert is only possible through expertise gained through first-hand experience: 
If our "experts" are chased out from here, I think I will quit as well since it is these people that have maintained the good level of the forum. If we ONLY ask for advice and share tips without any expertise; I mean deeper expertise; this discussion board will go down to the same level as any old chat boards. [8.6.2005; reinforcing the rules in the discussion board]

The second practice is that of reinforcing positive meanings. This practice is related to the evangelizing and justifying practices of brand communities. However, we provide a new angle to Schau et al. (2009), who found that these practices are directed to the outsiders who are not enthusiastic about the brand. The LCHF dieters seem to be more oriented toward the community itself. Members are sharing statements about all the positive changes the diet has made in their lives. Hereby, the newcomers also find support and encouragement for becoming more involved:

An LCHF person can have dainties every day, because when you eat good, delicious food you don't need any special "dainty days" with high-carb sweets and stuff. So I do not have those days, because what used to be dainties do not taste good, nor tempt me anymore. [24.8.2010; "dainty days"]

For some dieters, the LCHF is not a sacrifice even when it comes to special treats. On the contrary, they feel like they have solved the contradiction between healthy and tasty food by following the LCHF diet (Leipämaa-Leskinen, 2007). Some still make compromises between the values of LCHF and hedonistic consumption of food, but they might minimize the breach by emphasizing another value, such as effort:

These foods are so good that you don't really get any desires. And if you do, you can make the effort and bake the pastry yourself, or even ice-cream; then you get doublepleasure for eating it, because it's so good and also self-made. [24.8.2010; “dainty days"]

The legitimating comments made about LCHF use different arguments, including the healthiness, authenticity and low price of the LCHF foods, as well as its overall impact on well-being.

Let's all boast about the good effects of LCHF in our lives! You can report healthrelated things and other things. I will begin as a newcomer in LCHF:

- I have lost weight rapidly

- I don't feel hungry as usually when dieting 
- My nutrition has become much more varied! Even my husband is happy, although he does not do the LCHF himself.

- I have much more energy than I used to!

- I am more positive and I don't have those mood swings as I had when I was eating carbs. [13.5.2010; the positive things of LCHF in consumers' lives]

The third practice, tutoring, is related to the community building practices in brand communities, where more experienced members socialize newcomers (Schau et al., 2009). In the LCHF community, members give each other tips and guidance.

What should I do when I'm feeling fed up with this coconut oil? I don't feel like eating it at all; just the opposite.

[a response] How much can you eat it daily? Do you always drink it straight? I take a spoonful in the morning and at other times I mix it with berries and cream or in hot chocolate/tea.

[another response] Maybe you should take a break from coconut oil and try getting the fat from peanuts, meat, avocados, butter, cream etc. instead. [9.11.2009; drinking fatty cooking oils]

Recipes are shared and discussed together to make sure that the newcomers understand the relevant things about the diet. The more experienced members also want to fix misunderstandings:

It would be interesting to hear where you read/learned/got information about LCHF? Because if there is a source somewhere out there that gives the wrong guidance, we could go and fix it. [22.9.2010; where newcomers got the inspiration to adopt the LCHF lifestyle]

Beginners have a designated section of the discussion board to discuss their problems, but more experienced members also visit it to answer their questions. Thereby, the barriers of entry to the community are lowered and members who do not wish to interact with newcomers are not bothered by the same questions reoccurring. The community also has special discussion chains explaining the basics of the diet, as well as a link library. From time to time, more experienced members also make summaries, such as "The 10 commandments for LCHF dieter", a lengthy post that was received with enthusiasm by other members. 
I think I'm gonna print this post and put it on my fridge. Thanks!

This is all the advice in short form; the guidelines for beginners and also answers for those who are in doubt. You have done a great job! [8.1.2008; responses to "10 commandments for LCHF dieter"]

\section{Community-directed and challenging practices}

The fourth and final category of practices suggests that lifestyle consumption communities can be characterized by heterogeneity, conflicts and debates and still be held together and function communally (deValck, 2007). Through negotiation, the community is developed and remains dynamic. The first practice is developing and challenging the culture. Members negotiate the rules, norms and values of the community together. There is potential for conflict especially as the members engage in status games, where they want to represent themselves as more knowledgeable and experienced than others (deValck, 2007). Simultaneously, members wish for a supportive atmosphere and several different sets of rules are accepted. Reflexive questioning of all knowledge is appreciated (Thompson and Troester, 2002):

I hope everyone remembers that this is a peer support group and we all mould it through our own behavior constantly. I'd like for the board to be a place where you can ask for advice and share tips without anyone raising themselves above others or being "always right". Claiming absolute truths is dangerous because knowledge is constantly changing through new scientific results and experience. Let's maintain an open, discussing and constructive atmosphere! [8.6.2005; reinforcing the rules in the conversation board]

A tip given by a bodybuilder may be wrong for somebody who is trying to lose weight without exercising, even thought it may be completely right for somebody else. These are complex things for a beginner...it demands expertise to know them apart.

[8.6.2005; reinforcing the rules in the conversation board]

The members also discuss how new members are accepted. Beginners often keep asking the same questions and are sometimes received negatively:

I have followed this discussion board for a while and I wonder why these people calling themselves LCHF dieters are so angry and downright mean??? [3.12.2004; why the members are so grumpy and angry] 
Here you cannot ask anything somebody else has already asked. And if you do, you'll get called stupid. And people are very straight-laced if you criticize LCHF.

[27.10.2005; whether you are allowed to be a beginner]

The distinction between newcomers and experts is thus a major challenge for the discussion board; on the one hand because newcomers provide new life on the board, on the other, because newcomers are seen as naïve or lazy if they do not find out things by themselves. Furthermore, newcomer socialization provides experienced members an important arena for exhibiting their status (deValck, 2007), which is why the discussion board dynamics need both types of members. In trying to solve the contradictions, the members refer to the shared values of the community, such as open debate and multiple perspectives or "truths":

...if you look more closely, you will see that there's also supportive communality and very few "wars". As in real life, also contradictions are being debated and we don't stop the debate even when it runs out of sensible things to say, unlike they do in other areas... [14.11.2004; why the members are so grumpy and angry]

When it comes to expertise, I think everyone is an expert of their own. Of course you can ask for guidance and tips but their value is judged only when the person puts them in practice. That's why the concept of truth (regarding diets and metabolism) should be abandoned and instead report your own experiences and habits that you've found good (supported by facts if needed). Nobody should condemn something that has worked for someone else. [8.6.2005; reinforcing the rules in the discussion board]

Constant negotiation and debate thus seem to be core values in the community. Some participants even wish for more outsiders to the discussion board, to make the culture even more open for negotiation:

I would like for even more well-argued critical opinions of LCHF from outsiders. Too much consensus will quickly produce an idealistic image of anything. [8.6.2005; reinforcing the rules in the discussion board]

The second practice in this category is that of managing negative meanings. The members engage in this practice to discuss the negative sides of the diet, and to try and refute these. As argued by theorists of late modernism, today's consumers are faced with a risk-society (Beck, 1992; Giddens, 1991) where they have to find their way in the midst of abstract systems that produce information about the health effects of diets. The portrait of LCHF in the media has been fairly one-sided; 
depicting the consumers who follow the lifestyle as extremists and reinforcing the stereotypes. The value of food authenticity is emphasized by some to refute this point:

I'm ANNOYED that people talk about LCHF as being nonecological. Is it nonecological to buy real butter for instance, when no extra crap has been added to it, let alone organic meat, vegetables and so on?! Well, I guess it is most important that you yourself know you're eating healthy and right, and ECOLOGICALLY. [12.7.2010; whether LCHF is an ecological/ethical lifestyle]

On the other hand, the members do not necessarily share similar interpretations of what is ecological, either:

Isn't all this ecology talk basically about the fact that there are too many people on this planet and that's the reason for having to develop more energy-efficient ways of producing food. Why should everyone start eating crap that is not healthy so that we could accommodate a couple of billion more people?! [24.9.2010; whether LCHF is an ecological/ethical lifestyle]

The value of mindfulness (Thompson and Troester, 2002) is clearly seen in the discussions. It means that the consumers are emphasizing how LCHF is a conscious, informed choice for them and not just following conventions or doing it because it is "fashionable".

I don't think LCHF is about abstinence. It is about being free to choose differently from the official recommendations. I think it should also mean being free to question the Sacred LCHF Truths if that's what your body wants. [6.3.2008; 10 commandments for LCHF dieter]

The third practice in this category is that of negotiating relationships with extra-groups. As LCHF dieters, consumers have to face outsiders who do not understand or accept the diet, which is why there are strategies for confronting them. There are special argument lists that members can use to convince outsiders, such as their family members or co-workers about the diet's health effects. The discussion board members can also be very passionate about defending their lifestyle choice together:

I think we are at the edge of another Finnish fat war. But we have to wage war against many opponents, including the pharmaceutical industry. And these other opponents are much tougher than the ragtag nutrition specialists. [7.8.2008; 
commenting a television program about nutrition recommendations]

A related legitimizing practice is that of criticizing mainstream consumers who just go with the flow. For instance, in a discussion chain titled "Shopping cart stalkers", the discussion board members analyze and criticize outsiders' food purchases, and the chain has over 2000 messages. On the other hand, some members have a differing opinion, so there is again room for negotiation:

I feel that many of us here think that what they buy from the grocery store is a frontpage story. Get real! This LCHF diet is not the Only truth for everyone, even thought it might be for us. [25.3.2011; a critical response to the "Shopping cart stalkers" chain]

Because food and eating also has a strong social function (Kniazeva and Venkatesh, 2007), sometimes LCHF dieters are forced to make compromises between their loyalty to the lifestyle and maintaining their social relationships and other responsibilities. The responsibility to evangelize (Schau et al., 2009) and spread the LCHF diet in one's social networks is also negotiated. Some consumers feel that it is their duty, whereas others think it is just too much trouble. Still others think that they need to be careful about recommending the diet:

I convert, preach, rave and plead. And I'm not at all ashamed! [10.8.2005; how many members convert other people into the LCHF lifestyle]

I'm not willing to take the responsibility if someone with a heart condition starts the LCHF without becoming sufficiently familiar with it and becomes dangerously ill...I would have to make so much effort to be able to give them a FULL info package about the diet; I don't think I have the resources for that. [11.2.2010; LCHF dieters who work as professionals in health care]

\section{DISCUSSION}

\section{Theoretical contributions}

Our results show that online community dynamics can be effectively studied by analyzing the members' shared practices. A typology of eleven practices was delineated, showing the process through which lifestyle identities are built in online communities. We also found that the practices that members engage in have a great influence not only on the members' identity but also on the community's future. By engaging in individual-oriented practices, the lifestyle identity is built, whereas by engaging in community-oriented practices, the whole community is developed e.g. 
toward new discussion mechanisms or more debate. Making the distinction between maintaining and challenging practices provides a new contribution to analysis of communal practices.

Unlike brand community members to whom the brand is only relatively small part of their lifestyle, consumption lifestyle community members are faced with everyday decisions on which norms to follow and which practices to adopt. Eating and planning it takes up a lot of time from their daily lives. They also have to encounter other people who do not follow the lifestyle and be able to cope with possible conflicts and socially awkward situations. Constant negotiation is, however, considered a strong value in the community. Learning from the community and forming emotional relationships is definitely part of online community interaction, but our findings indicate that members are also expected to find their own style and contribute to community development. Online community members may also form factions based on different micro-level tasteworlds and personal styles (deValck, 2007; Kozinets, 1999).

Based on our results, it can be argued that some online communities thrive on negotiation, contradictions and even conflicts to stay dynamic and evolve. Through solving problems that arise from contradictions, the members develop the community together. The community may also be very self-critical and self-judging at times, making it more heterogeneous than a typical brand community with a strict social structure. This finding enhances theories on online consumption communities by showing their diverse nature.

Our implications follow up on the idea that online community members are not all the same and thus have different drivers, motivations and needs (deValck, 2007; Heinonen, 2011; Ouwersloot and Odekerken-Schröder, 2008). However, we find that contradictions that arise from this heterogeneity are not always bad for an online community. They may fuel members' interest and stimulate the discussion. According to Kozinets (1999), the most interesting groups to marketers are the insiders and very devoted members. However, beginners are also needed because they provide differing opinions and challenges for more experienced members.

Our results provide valuable insights on the dynamics of online communities that revolve around complex, nuanced and holistic lifestyles instead of single brands or consumption activities. Food needs to be good to eat but also "good to think" (Lévi-Strauss, 1968). This is highlighted in the postmodern culture of fragmented beliefs related to food and nutrition. Eating is an area full of contradictions, for instance between healthiness versus indulgence, or economy versus extravagance (Warde, 1997). Lifestyles come with particular social and cultural discourses that influence how they are enacted, and cause even stigmatized identities to emerge (Thompson and Troester, 2002). Online communities provide members an important arena for negotiating these lifestyles and the contradictory meanings related to them. We argue that participating in them is one solution for 
reducing the risks related to food and health (Brunel and Pichon, 2004). Our results support Cherrier (2007) who argues that the individual and collective parts of identity are mutually constitutive and co-produced in constant negotiation with others. We find that discursive practices are a way to renew meanings and culture but they also produce new culture (Halkier and Jensen, 2011).

As it concentrates on a major lifestyle trend, our research can also be reflected with contemporary lifestyle movements, such as sustainable consumption (Black and Cherrier, 2010; Connolly and Prothero, 2008), slow food movement (Sassatelli and Davolio, 2010) or voluntary simplicity (Cherrier, 2007). Consumption is becoming political as people make choices where they take into account environmental and ethical aspects in building their lifestyles. It has also been interpreted as part of a counter-modernizing tendency (Thompson and Troester, 2002). An example of this is the way the LCHF dieters criticize official nutrition recommendations that are based on modern medical science. Our study contributes specifically by looking at one important forum where this politicization of consumption is taking place; an online community. We show how the cultural meanings around food consumption become mobilized in the interactions between ordinary consumers.

\section{Implications for practitioners}

Companies are increasingly concerned about connecting with their customers in order to understand them better. Online media offers wonderful tools for this, but while consumers are actively interacting with other consumers online, what can companies learn from this? Our results implicate that there is a lot to learn about consumption practices just by following consumer-to-consumer online discussions. For instance, information about preferences regarding brands and ingredients, habits of how the food is consumed as well as what is considered fake or inauthentic can be effectively gathered. In terms of sharing information, communities are effective, which is why they should be considered major partners in developing and marketing new lifestyle products. In case the marketer wants to host a customer community, careful planning is needed. Because of the great influence of member status and length of membership, marketers interested in using social media should plan for their online platforms to contain mechanisms that facilitate interaction between different types of members, as well as support member socialization and knowledge sharing within the community. Rewarding members who are willing to teach newcomers, offering mechanisms of asking and giving feedback and inspiring members to share their knowledge by e.g. contests or competitions could be fruitful ways of engaging with the consumers. 


\section{Future research}

Our study focused on the shared practices of adopting the LCHF lifestyle. We did not track the individual members of the community to see how their practices change in relation to their experience. The choice of not following individual discussants was also made in order to protect their privacy. Future research could explore for instance how the identity paths of individuals are constructed as they become more active on the discussion board, or study different consumption lifestyle communities such as those related to green consumption and see whether the practices can be further refined.

\section{REFERENCES}

Alon A, Brunel F, Schneier SW. 2005. Ritual behavior and community life-cycle: exploring the social psychological roles of net rituals in the development of online consumption communities, in C. Haugvedt, K. Machleit and R. Yalch (eds.), Online consumer psychology: Understanding how to interact with consumers in the virtual world. NJ: Hillsdale; 5-33.

Algesheimer R, Dholakia UM, Herrmann A. 2005. The social influence of brand community: Evidence from European car clubs. Journal of Marketing, 69 (3): 19-34.

Arnould EJ, Wallendorf M.1994. Market-oriented ethnography: Interpretation building and marketing strategy formulation. Journal of Marketing Research, 31 (4): 484-504.

Bagozzi RP, Dholakia UM. 2006. Antecedents and purchase consequences of customer participation in small group brand communities. International Journal of Research in Marketing, 23 (1): 45-61.

Ballantine PW, Stephenson RJ. 2011. Help me, I'm fat! Social support in online weight loss networks. Journal of Consumer Behaviour, 10 (6), 332-337.

Beck U. 1992. Risk society: Towards a new modernity. London: Sage. 
Belasco W. 2008. Food: the key concepts. New York: Berg.

Black IR, Cherrier H. 2010. Anti-consumption as part of living a sustainable lifestyle: Daily practices, contextual motivations, and subjective values. Journal of Consumer Behaviour, 9 (6): 437-453.

Brunel O, Pichon P-E. 2004. Food-related risk-reduction strategies: purchasing and consumption processes. Journal of Consumer Behaviour, 3 (4): 360-374.

Catterall M, Maclaran P. 2002. Researching consumers in virtual worlds: A cyberspace odyssey. Journal of Consumer Behaviour, 1 (3): 228-237.

Chan KW, Li SY. 2010. Understanding consumer-to-consumer interactions in virtual communities: The salience of reciprocity. Journal of Business Research, 63 (9-10): 1033-1040.

Cherrier H. 2007. Ethical consumption practices: Co-production of self-expression and social recognition. Journal of Consumer Behaviour, 6 (5): 321-335.

Connolly J, Prothero A. 2008. Green consumption: Life-politics, risk and contradictions. Journal of Consumer Culture, 8 (1): 117-145.

Corbin JM, Strauss AL. 2008. Basics of qualitative research: Techniques and procedures for developing grounded theory. Los Angeles, CA: Sage.

Cova, B. 1997. Community and consumption: Towards a definition of the "linking value" of products and services. Journal of European Marketing, 31 (3/4): 297-316.

Cova B, Cova V. 2002. Tribal marketing. The tribalisation of society and its impact on the conduct of marketing. European Journal of Marketing, 36 (5-6): 595-620.

Cova B, Elliott R. 2008. Everything you always wanted to know about interpretive consumer research but were afraid to ask. Qualitative Market Research: An International Journal, 11 (2): 121-129. 
Cova B, Pace S. 2006. Brand community of convenience products: new forms of customer empowerment - the case "my Nutella the community". European Journal of Marketing, 40 (9/10): 1087-1105.

deValck K. 2007. The war of the e-tribes: Online conflicts and communal consumption, in Consumer Tribes, B. Cova, RV. Kozinets and A. Shankar (eds.), London: Elsevier; 260-73.

Edelman Trust Barometer. 2012. Available at http://trust.edelman.com/trust-download/globalresults/ [accessed on 1 August 2012].

Etzioni A, Etzioni, O. 1999. Face-to-face and computer-mediated communities: A comparative analysis. The Information Society: An International Journal, 15 (4): 241-248.

Fernbank J. 1999. There is a there there: Notes toward a definition of cybercommunity, in Doing Internet Research: Critical Issues and Methods for Examining the Net, S. Jones (ed.). Thousand Oaks: Sage, 203-220.

Firat AF, Dholakia N. 2006. Theoretical and philosophical implications of postmodern debates: Some challenges to modern marketing. Marketing Theory, 6 (2): 123-162.

Firat AF, Venkatesh A. 1995. Liberatory postmodernism and the reenchantment of consumption. Journal of Consumer Research, 22 (3): 239-267.

Fischler C. 1988. Food, self, and identity. Social Science Information/Sur les Sciences Sociales, 27 (2): $275-292$.

Foucault M. 1980. Power/knowledge: Selected Interviews and Other Writings 1972-1977. London: Harvester.

Giddens A. 1991. Modernity and Self-Identity: Self and Society in the Late Modern Age. Cornwall: Polity.

Goulding C, Shankar A, Elliott R. 2002. Working weeks, rave weekends: Identity fragmentation 
and the emergence of new communities. Consumption, Markets and Culture, 5 (4): $261-284$.

Halkier B, Jensen I. 2011. Methodological challenges in using practice theory in consumption research: Examples from a study on handling nutritional contestations of food consumption. Journal of Consumer Culture, 11 (1): 101-123.

Hall S. 1992. The question of cultural identity, in Modernity and Its Futures, S. Hall, D. Held, T.McGrew (eds.). Cambridge, England: Polity; 273-316

Heinonen K. 2011. Conceptualizing consumers' dynamic relationship engagement: the development of online community relationships. Journal of Customer Behavior, 10 (1): 49-72.

Honkanen P, Verplanken B, Olsen, SO. 2006. Ethical values and motives driving organic food choice. Journal of Consumer Behavior, 5 (5): 420-430.

Hughner RS, McDonagh P, Prothero A, Schultz CJ II, Stanton J. 2007. Who are organic food consumers? A compilation and review of why people purchase organic food. Journal of Consumer Behaviour, 6 (2-3): 91-110.

Jenkins R. 1996. Social Identity. London: Routledge.

Järvelä K, Mäkelä J, Piiroinen S. 2006. Consumers' everyday food choice strategies in Finland. International Journal of Consumer Studies, 30 (4): 309-317.

Kniazeva M and Venkatesh A. 2007. Food for thought: a study of food consumption in postmodern U.S. culture. Journal of Consumer Behaviour, 6 (6): 419-435.

Kozinets RV. 1999. E-tribalized marketing? The strategic implications of virtual communities of consumption. European Management Journal, 17 (3): 252-265.

Kozinets RV. 2001. Utopian enterprise: Articulating the meanings of Star Trek's culture of consumption. Journal of Consumer Research, 28 (1): 67-88. 
Kozinets RV. 2002. The field behind the screen: Using netnography for marketing research in online communities. Journal of Marketing Research, 39 (1): 61-72.

Kozinets RV. 2010. Netnography: Doing ethnographic research online. London: Sage.

Kozinets RV, Hemetsberger A, Schau HJ. 2008. The wisdom of consumer crowds: Collective innovation in the age of networked marketing. Journal of Macromarketing, 28 (4): $339-354$.

Kozinets RV, deValck K, Wojnicki AC, Wilner SJS. 2010. Networked narratives: Understanding word-of-mouth marketing in online communities. Journal of Marketing, 74 (2): 7189.

Langer R, Beckman SC. 2005. Sensitive research topics: Netnography revisited. Qualitative Market Research: An International Journal, 8 (2): 189-203.

Leipämaa-Leskinen H. 2007. Contradictions in food consumption. International Journal of Consumer Studies, 31 (6): 597-602.

Liang B, Scammon DL. 2011. E-Word-of-Mouth on health social networking sites: An opportunity for tailored health communication. Journal of Consumer Behaviour, 10 (6), 322-331.

Lévi-Strauss C. 1968. L’Origine des manières de table. Mythologiques IV. Paris: Seuil.

McAlexander JH, Schouten JW, Koenig HF. 2002. Building brand community. Journal of Marketing, 66 (1): 38-54.

McKenna, KYA, Bargh, JA. 1998. Coming out in the age of the Internet: Identity “demarginalization" through virtual group participation. Journal of Personality and Social Psychology, 75 (3): 681-694.

Muñiz AM, O’Guinn TC. 2001. Brand community. Journal of Consumer Research, 27 (4): 412432. 
Muñiz AM, Schau HJ. 2005. Religiosity in the abandoned Apple Newton brand community. Journal of Consumer Research, 31 (4): 737-747.

Ouwersloot H, Odekerken-Schröder G. 2008. Who's who in brand communities - and why? European Journal of Marketing, 42 (5/6): 571-585.

Rheingold H 2002. Smart mobs: the next social revolution. Cambridge, MA: Basic Books.

Rokka J, Moisander J. 2009. Environmental dialogue in online communities: Negotiating ecological citizenship among global travellers. International Journal of Consumer Studies, 33 (2): 199-205.

Rozin P.1999. Food is fundamental, fun, frightening, and far-reaching. Social Research, 66 (1): 930.

Sandlin J. 2007. Netnography as a consumer education research tool. International Journal of Consumer Studies, 31 (3): 288-294.

Sassatelli R., Davolio F. 2010. Consumption, pleasure, and politics: Slow food and the politicoaesthetic problematization of food. Journal of Consumer Culture, 10 (2): 202-232.

Schau HJ, Gilly M. 2003. We are what we post? Self-presentation in personal web space. Journal of Consumer Research, 30 (3): 385-404.

Schau HJ, Muñiz AM, Arnould EJ. 2009. How brand community practices create value. Journal of Marketing, 73 (5): 30-51.

Shankar A, Elliott R, Goulding C. 2001. Understanding consumption: Contributions from a narrative perspective. Journal of Marketing Management, 17 (3-4): 429-453.

Spiggle S. 1994. Analysis and interpretation of qualitative data in consumer research. Journal of Consumer Research, 21 (3): 491-503. 
Thompson GJ. 2005. Consumer risk perceptions in a community of reflexive doubt. Journal of Consumer Research, 32 (2): 235-248.

Thompson GJ, Hirschman E. 1995. Understanding the socialized body: A poststructuralist analysis of consumers' self-conceptions, body images, and self-care practices. Journal of Consumer Research, 22 (2): 139-153.

Thompson GJ, Troester M. 2002. Consumer value systems in the age of postmodern fragmentation: The case of natural health microculture. Journal of Consumer Research, 28 (4): 550571.

Warde A. 1997. Consumption, food, and taste: culinary antinomies and commodity culture. London: Sage.

Warde A. 2005. Consumption and theories of practice. Journal of Consumer Culture, 5 (2): 131153.

Wright KB, Rains S, Banas J. 2010. Weak-tie support network preference and perceived life stress among participants in health-realted, computer-mediated support groups. Journal of Computer-Mediated Communication, 15 (4): 606-624.

Yin R. 1994. Case study research: design and methods. Thousand Oaks, CA: Sage. 
TABLE 1. Details about the data

\begin{tabular}{|l|l|}
\hline $\begin{array}{l}\text { Functionalities of the } \\
\text { community }\end{array}$ & $\begin{array}{l}\text { Discussion board, e-shop for LCHF literature, electronic tools for } \\
\text { counting calories and nutritional substances, recipes section }\end{array}$ \\
\hline $\begin{array}{l}\text { Section themes } \\
\text { News, General discussion, Beginners, Overweight members, } \\
\text { Different styles, Cooking, Exercise, Reviews, Diaries, Gallery, } \\
\text { Visitors, Battleground, Clubs, Family-life, Feedback }\end{array}$ \\
\hline $\begin{array}{l}\text { Timeline of analyzed } \\
\text { messages }\end{array}$ & $11 / 2004-3 / 2011$ \\
\hline $\begin{array}{l}\text { Amount of } \\
\text { discussion chains } \\
\text { analyzed }\end{array}$ & 83 (out of 48721 chains in total) \\
\hline $\begin{array}{l}\text { Amount of single } \\
\text { messages }\end{array}$ & 2347 (out of 1 182 222 messages in total) \\
\hline $\begin{array}{l}\text { Amount of different } \\
\text { pseudonyms }\end{array}$ & 71 \\
\hline
\end{tabular}

Figure 1. Typology of discursive practices

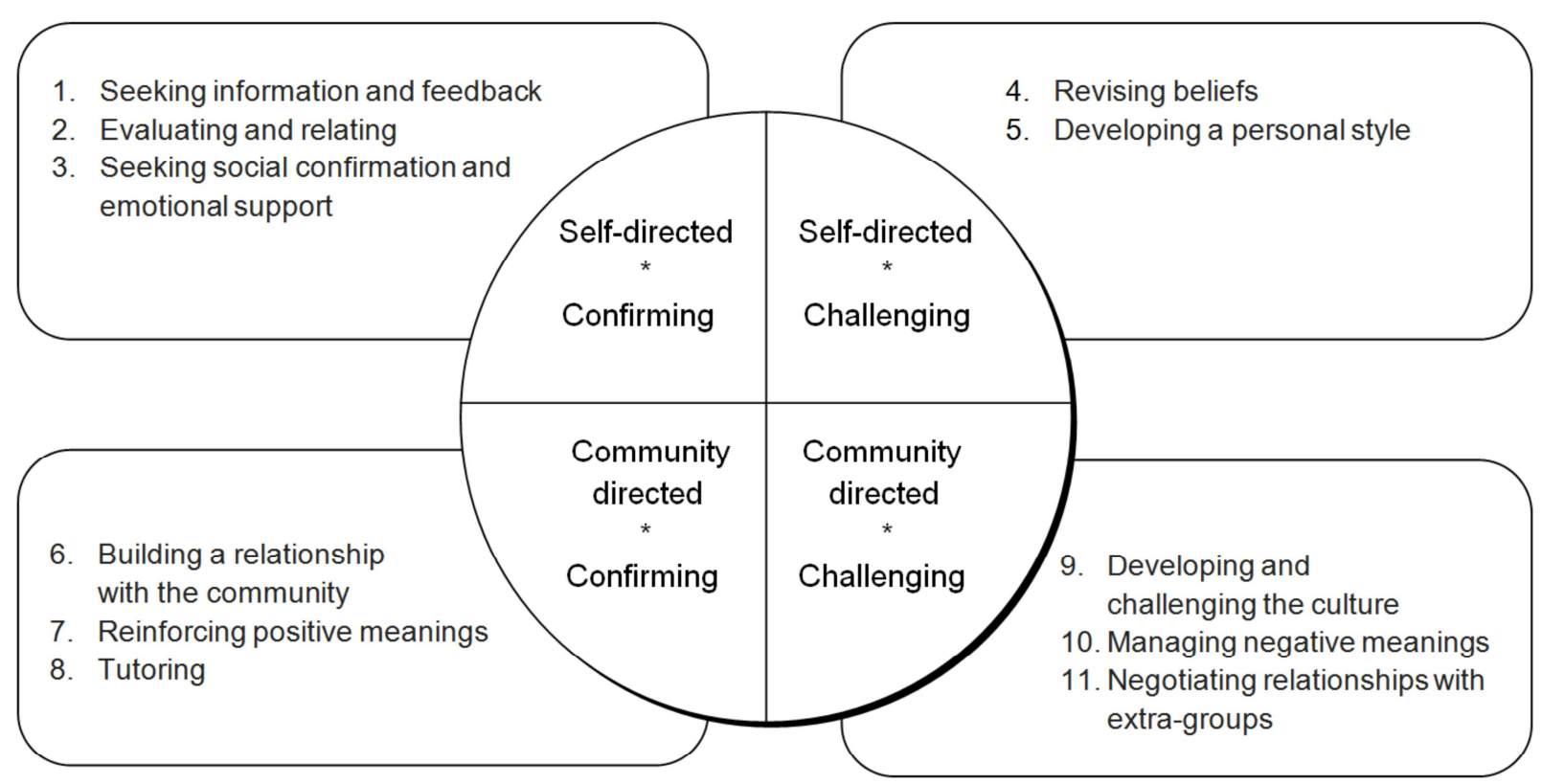

